\title{
Risk factors associated with drug therapy among elderly people with Alzheimer's disease: a cross-sectional study
}

\author{
Marcela Forgerini', Maria Teresa Herdeiro", José Carlos Fernandes Galduróz"', Patrícia de Carvalho Mastroiannilv \\ Universidade Estadual Paulista (UNESP), Araraquara (SP), Brazil
}

IPharmacist and Doctoral Student, Department of Drugs and Medicines, School of

Pharmaceutical Sciences, Universidade Estadual Paulista (UNESP), Araraquara (SP), Brazil.

(D) orcid.org/0000-0002-2905-8519

"PhD. Pharmacist and Professor, Department of Medical Sciences, Universidade de Aveiro, Institute of Biomedicine (iBiMED), Aveiro, Portugal.

(D) orcid.org/0000-0002-0500-4049

I'PhD. Adjunct Professor, Department of Psychobiology, Universidade Federal de São Paulo (UNIFESP), São Paulo (SP), Brazil.

(D) orcid.org/0000-0002-2710-9693

"PhD. Pharmacist and Adjunct Professor, Department of Drugs and Medicines, Universidade Estadual Paulista (UNESP), Araraquara (SP), Brazil.

(D) orcid.org/0000-0001-8467-7278

KEY WORDS (MeSH terms):

Dementia.

Patient safety.

Polypharmacy

\section{AUTHORS' KEY WORDS:}

Complexity index.

Medication regimen.

Potentially inappropriate medication.

\begin{abstract}
BACKGROUND: Improving knowledge and establishing strategies and policies for better patient safety are worldwide priorities.

OBJECTIVE: To evaluate drug safety among elderly people with Alzheimer's disease (AD).

DESIGN AND SETTING: Cross-sectional study among elderly people within the National AD Assistance Protocol (PCDTDA/MS) who were living in the municipality of Araraquara, Brazil, in 2017.

METHODS: Through interviews conducted with relatives/caregivers of elderly people with diagnoses of $A D$, the following variables were evaluated: comorbidities, drug therapy used, use of potentially inappropriate medications for the elderly (PIMs), presence of potentially inappropriate interactions (PIIs) and medication regimen complexity index. Factors associated with AD severity were also evaluated. Multivariate and simple logistic regressions were applied.

RESULTS: 143 elderly people enrolled in PCDTDA/MS were analyzed. The majority were women (67.1\%); assisted only through the public healthcare system (75.5\%); polymedicated (57.4\%); using at least one PIM (63.6\%); presenting at least one PII (63.6\%); and under drug therapy of low to medium complexity (92.2\%). No semi-annual monitoring of the effectiveness of PCDTDA/MS drugs was identified. The proportion using AD drug therapy at daily doses differing from those recommended by the World Health Organization was $75.6 \%$. However, these doses were not associated with drug risk.

CONCLUSION: The data from this study raise the hypothesis that use of polypharmacy might show a correlation with severity of AD. The drug safety risk may be associated with comorbidities of the metabolic syndrome, anxiety and off-label use of PIMs, such as risperidone and quetiapine, and benzodiazepines (i.e. clonazepam and flunitrazepam).
\end{abstract}

\section{INTRODUCTION}

Prescription of potentially inappropriate medications for the elderly (PIMs), ${ }^{1}$ the complexity of drug therapy regimens, ${ }^{2}$ the risk of potentially inappropriate interactions (PIIs), ${ }^{3}$ use of polypharmacy ${ }^{4}$ and occurrences of adverse drug events (ADEs) ${ }^{5}$ are factors that compromise drug safety among elderly people.

The risk of hospitalizations due to ADE is two to seven times greater among elderly people. ${ }^{6}$ It has been estimated that for every two hospitalized elderly individuals, the reason for admission of one of them was possibly an occurrence of one or more ADEs.?

PIMs are drugs with risks that can outweigh the benefits, especially when there are safer and more effective alternatives. ${ }^{8}$ They are also associated with occurrences of ADEs, ${ }^{9}$ and their use contributes to a twofold increase in the risk of hospitalization among elderly people. ${ }^{10}$

In addition, some drugs that have been standardized as essential by the World Health Organization (WHO) and in the Brazilian National List of Essential Medicines (RENAMEBrazil) are considered to be PIMs. However, there is often no other safer drug alternative. ${ }^{11}$

With the aging of the population, there are projections of high prevalence and incidence of dementia, ${ }^{12}$ among which Alzheimer's disease (AD) is the most prevalent form. ${ }^{13}$ However, within the context of drug therapy for these conditions, we are not aware of any study on such therapy with concomitant evaluation of drug risk factors, i.e. polypharmacy, PIM use, PII, drug therapy complexity index and comorbidities. Nor have associations of these factors with disease severity among elderly people with dementia or AD been assessed. ${ }^{14-17}$ 


\section{OBJECTIVE}

The objectives of the present study were to characterize elderly people with a diagnosis of $\mathrm{AD}$; identify comorbidities, drug therapy complexity, use of PIMs and presence of PIIs; and raise hypotheses regarding possible drug risk factors. Through this, we aimed to contribute to national and international patient safety goals.

\section{METHODS}

\section{Study design and ethics}

A cross-sectional study was conducted in Araraquara, Brazil, over the course of the year 2017.

The study design was based on the guidelines for Strengthening the Reporting of Observational Studies in Epidemiology (STROBE). ${ }^{18}$ The protocol for this study was approved by the Research Ethics Committee of the Universidade Federal de São Paulo in 2016 (no. 2.877.560).

\section{Setting and participants}

The study was conducted at the Araraquara Reference Center for Elderly Patients (CRIA) and at the Regional Health Directorate III (DRS-III) for services of specialized nature.

Elderly individuals with a diagnosis of $\mathrm{AD}$ are referred by the healthcare services to the CRIA. CRIA provides medium-complexity services and specializes in geriatric care, using protocols for treating forgetfulness, dementia, stroke sequelae and mild depression.

In DRS-III, drug therapy for AD is dispensed. In 2017, 260 elderly people were registered at the DRS-III of Araraquara within the Clinical Protocol and Therapeutic Guidelines for Alzheimer's Disease of the Ministry of Health (PCDTDA/MS), ${ }^{19}$ including both new and old cases.

These guidelines are documents based on scientific evidence that establish criteria for diagnosing the health problem and make recommendations for treatments and dosages and for monitoring the therapeutic results.

The elderly people who were registered within the PCDTDA/ MS had been diagnosed with AD (ICD-10: G30) in accordance with the criteria of the National Institute on Aging and the Alzheimer's Disease and Related Disorders Association, which have been endorsed by the Brazilian Academy of Neurology. ${ }^{20}$

$\mathrm{AD}$ is diagnosed through the following procedures: evaluation of the clinical history; cognitive screening through the clinical parameters of the Mini-Mental State Examination (MMSE) $)^{21}$ and the Clinical Dementia Rating (CDR);22 laboratory tests (vitamin B12, folic acid, electrolytes, blood glucose, urea, creatinine, alanine aminotransferase, aspartate aminotransferase and thyroid-stimulating hormone); and magnetic resonance imaging or computed tomography scans. ${ }^{19}$
In addition, the drug therapy that has been approved for treating $\mathrm{AD}$, i.e. donepezil, galantamine and rivastigmine (acetylcholinesterase inhibitors) and memantine, is available free of charge to elderly patients who are included in the PCDTDA/MS. AD drug therapy dispensing is performed through the public healthcare system in order to ensure access and integrality of the treatment at the outpatient level.

Thus, elderly individuals who had been registered within the PCDTDA/MS were included in this study. Elderly individuals who were living in long-term institutions were excluded for ethical reasons, given the advanced stage of their disease and the absence of a relative or caregiver to participate in the interview.

\section{Data}

This study was conducted through interviews with relatives or caregivers of elderly patients who were seen at CRIA and at the time of dispensing of AD drug therapy in DRS-III. The interview was led by one researcher.

A standardized questionnaire was drawn up for the interviews, and it sought the following information about the elderly subjects: gender; access to healthcare (only through the public healthcare system, only through the private system or through a mixture of the public and private systems); age; body mass index (BMI); schooling; monthly income; time of diagnosis of AD; family history of $\mathrm{AD}$; severity of $\mathrm{AD}$; clinical parameters (MMSE ${ }^{21}$ and $\mathrm{CDR}^{22}$ ); drug therapy and time of use; medication regimen complexity index (MRCI); defined daily dose (DDD) of AD drug therapy, stratified as above the requirement, below the requirement or adequate dose, as defined by WHO; comorbidities and time of diagnosis; and consumption of alcohol and tobacco.

The data obtained through the interview were confirmed using secondary sources, i.e. from medical records available at the healthcare service, prescriptions and clinical laboratory tests on the elderly subjects.

\section{Measurements}

\section{Comorbidities}

Comorbidities were identified through the relatives' or caregivers' reports or through self-reports; and from secondary data sources (medical records).

\section{Severity of Alzheimer's disease}

The severity of Alzheimer's disease was assessed through insertion of memantine either in association with anticholinesterases or as monotherapy. The insertion of memantine was evaluated to ensure that this was not associated with anticholinesterase intolerance, but rather with the severity of $\mathrm{AD}$, in accordance with the MMSE and CDR scores that had been pre-established within the PCDTDA/MS. ${ }^{19}$ 


\section{Metabolic syndrome}

Metabolic syndrome (MetS) consists of a set of factors that increase the risk of coronary heart disease. ${ }^{23}$

The guidelines developed through the National Cholesterol Education Program for detection of MetS recommend measurement of abdominal circumference, blood glucose levels, cholesterol levels (LDL and HDL) and blood pressure. ${ }^{23}$ However, since it was not possible to make these measurements in this study, the following criteria were used to define MetS: BMI of $30 \mathrm{~kg} / \mathrm{m}^{2}$ or greater) and use of antihypertensives antidiabetics and antidyslipidemics, as recommended in the literature.

Thus, presence of MetS was ascertained in terms of the presence of at least three of the factors described above.

\section{Medication regimen complexity index (MCRI)}

The complexity of drug therapy results from the multiplicity of prescribed regimen factors.

The MRCI is an open index divided into three domains: dosage form (pharmaceutical form according to route of administration), dosing frequency (number of times the drugs is given per day/week/month) and administration instructions (i.e. tablet fractionation, fasting, etc.). ${ }^{24}$ The more complex the dosage schedule and the process of drug use are, the higher the score assigned will be.

The minimum score is 1.5 points, which represents a single tablet or capsule taken once a day. There is no limit to the number of drugs to be analyzed.

We stratified the MRCI score as denoting low (1.5-14 points), medium (14-28 points) or high complexity (28-42 points).

The MRCI is the gold standard for assessing the complexity of drug therapy. ${ }^{25}$ However, it has some limitations, considering that observation of which scores correspond to higher scores shows that there is no maximum score or stratification of these scores. This was the reason why we made our own stratification for this study.

\section{Potentially inappropriate medications}

Prescription guides have been developed to identify any use of drugs that is considered inappropriate for elderly individuals. These are termed potentially inappropriate medications (PIMs), i.e. drugs for which the tradeoff between risk and benefit does not justify their use.

In our study, PIM assessments were made through the following prescription guides: updated Beers criteria, ${ }^{26,27}$ STOPP/START version $2,{ }^{28}$ French consensus panel ${ }^{29}$ and Canadian national consensus panel, ${ }^{30}$ and Strand criteria. ${ }^{31}$

These guides report on the drugs that are considered to be PIMs, depending on the clinical condition of the elderly individual, dose, length of time prescribed and PIM-comorbidity interactions.

\section{Drug risk variables}

In order to evaluate drug safety among patients with $\mathrm{AD}$, we defined the following variables as drug risk variables: PIM use and PII, evaluated through the updated Beers criteria, ${ }^{26,27}$ STOPP/ START version $2,{ }^{28}$ French consensus panel ${ }^{29}$, Canadian national consensus panel ${ }^{30}$ and Strand criteria; ${ }^{31}$ the complexity of drug therapy according to the medication regimen complexity index (MRCI) ${ }^{24}$ comorbidities identified through self-reports and with confirmation from medical records; and presence of polypharmacy, which was defined as use of five or more drugs for a period greater than or equal to 90 days.

\section{Data analysis}

\section{Sample size}

Given that a total of 260 elderly people had been registered within the PCDTDA/MS, the sample size for a confidence level of $90 \%$ $(\alpha=0.05)$ was 133 elderly people.

\section{Statistical analysis}

The variables of interest were described in terms of their absolute and relative frequencies.

Two statistical analyses were conducted: multivariate and simple logistic regressions.

To analyze the severity of AD in relation to the presence of drug risk variables (presence of polypharmacy, high-complexity MRCI, PIM use and occurrence of PII), multivariate logistic regression was used.

From another perspective, to evaluate the influence of each variable of this study on the severity of $\mathrm{AD}$ and/or in the presence of one or more variables that had been defined as drug risk variables, simple logistic regression was used. The aim of this analysis was to evaluate whether there were any variables that influenced the severity of $\mathrm{AD}$. For this, AD severity and the drug risk variables were considered to be the dependent variables and the others were independent variables.

Female gender, schooling $\leq 4$ years and presence of high-complexity MRCI were defined as independent variables in the simple logistic regression. Individual comorbidities were analyzed, as were comorbidities grouped in accordance with the International Statistical Classification of Diseases and Related Health Problems (ICD-10).

The statistical software used was BioEstat (version 5.3).

\section{RESULTS}

Out of the 260 elderly people who were enrolled in the PCDTDA/ MS, 16 were excluded because they were living in long-term institutions. Thus, 244 elderly individuals were eligible for inclusion in this study. Fourteen did not agree to participate and there were 
another 87 losses, due to the following: AD drug therapy was not received through the public healthcare system $(\mathrm{n}=49)$; $\mathrm{AD}$ drug therapy was dispensing to relatives or caregivers who did not know the clinical history of the elderly individual $(\mathrm{n}=31)$; or $\mathrm{AD}$ drug therapy was dispensed through a means of transportation that had been hired just to obtain it $(n=7)$ (Figure 1).

The age of the elderly individuals within the PCDTDA/MS ranged from 64 to 97 years. Their median age was 81 years $(\mathrm{Q} 1=76$; $\mathrm{Q} 3=$ 87) and they had had their diagnosis of $\mathrm{AD}$ for a median period of four years $(\mathrm{Q} 1=02$; $\mathrm{Q} 3=7.5)$. Most of these elderly people were women (67.1\%); did not have any family history of $\mathrm{AD}(60.1 \%)$; were assisted only through the public healthcare system (75.5\%); and had had less than four years of schooling (83.2\%). Twenty of these elderly people were illiterate and only six of them had had higher education.

In addition, most of them were polymedicated (57.4\%); were making use of at least one PIM (63.6\%) and had one PII (63.6\%). The mean number of drugs in use was five drugs/elderly person [standard deviation, SD: 2.69] and the drug therapy of
92.2\% of these elderly individuals was classified as presenting low or medium complexity.

Furthermore, although diabetes mellitus, arterial hypertension and dyslipidemia were among the most prevalent comorbidities, most of these elderly people did not have metabolic syndrome. However, it was also noted that most of them had one or more of the prodromal symptoms of AD: anxiety, insomnia and depression. These symptoms are frequently treated with drugs that are considered to be PIMs (Table 1).

Among the drugs used, which were available through PCDTDA/ MS, galantamine (46.1\%) and donepezil (33.61\%) were the ones most prescribed. Most of the elderly individuals were receiving monotherapy (88\%), at daily doses above the defined daily dose that are recommended by the WHO (60.2\%) (Table 2).

It was noted that no record of MMSE and CDR screening tests has yet been identified, thus making it impossible to evaluate the effectiveness of anticholinesterase treatment. Therefore, no semiannual reevaluation of the effectiveness of these tests that had been predicted through the PCDTDA/MS was done.

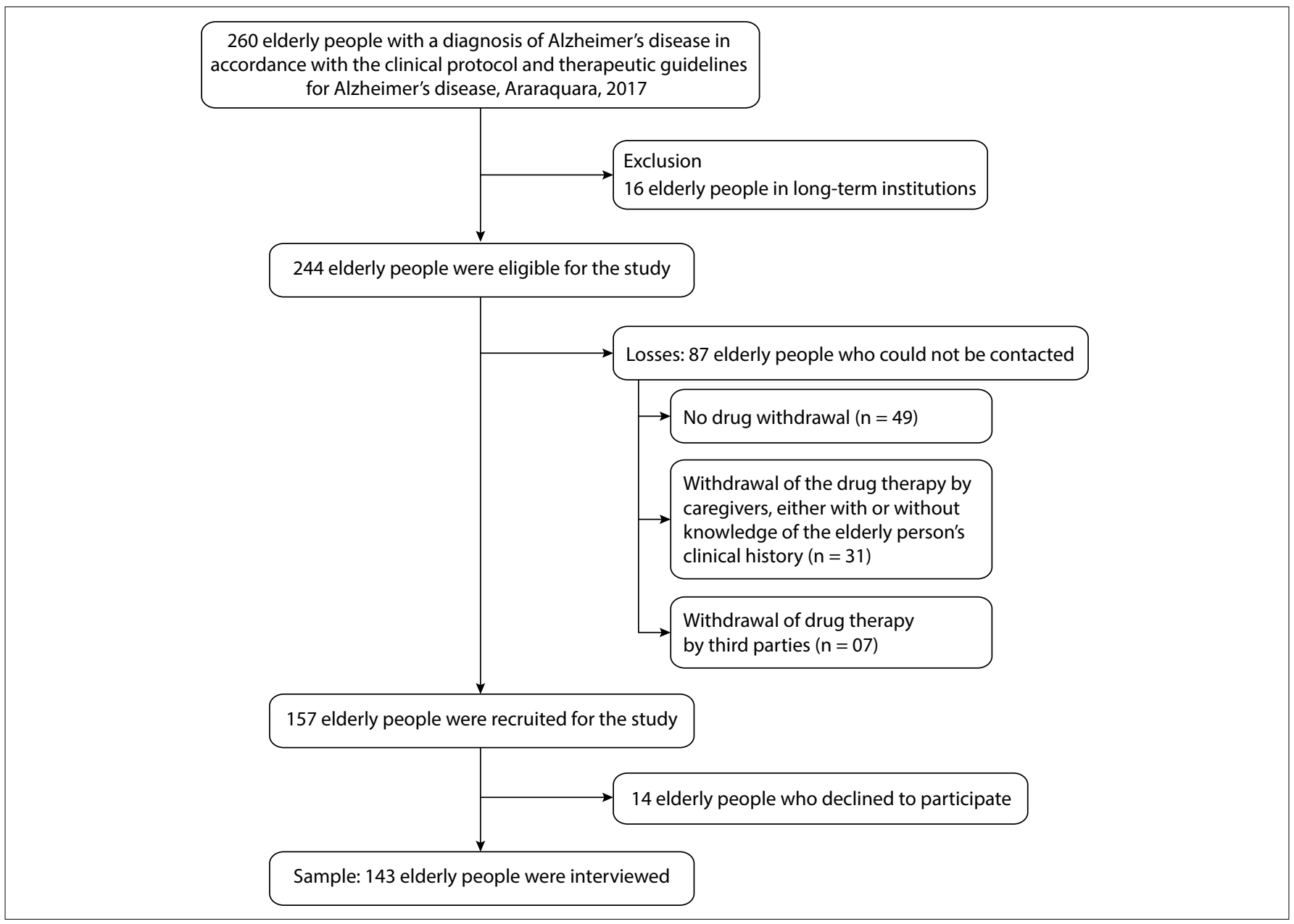

Figure 1. Flowchart of identification and eligibility of elderly people with Alzheimer's disease in accordance with the clinical protocol and therapeutic guidelines for Alzheimer's disease (PCDTDA/MS), in the municipality of Araraquara, 2017. 
Table 1. Clinical conditions of the elderly people with probable diagnoses of Alzheimer's disease $(n=143)$, Araraquara, 2017

$\begin{array}{lc}\text { Variable } & \mathbf{n}(\%) \\ \text { Gender } & \\ \text { Female } & 96(67.1) \\ \text { Male } & 47(32.9) \\ \text { Body mass index }\left(\mathbf{k g} / \mathbf{m}^{2}\right) & \\ \text { Median } & 24.2 \\ \text { Quartile } & (\mathrm{Q} 1=21.9 / \mathrm{Q} 3=28.3) \\ \text { Low-weight }(<18) & 6(4.2) \\ \text { Normal }(18-24) & 62(43.3) \\ \text { Overweight }(25-30) & 36(25.2) \\ \text { Obesity (30-35) } & 12(8.4) \\ \text { Moderate obesity (35-40) } & 5(3.5) \\ \text { Severe obesity }(>40) & 1(0.7) \\ \text { Without knowledge } & 21(14.7) \\ \text { Drugs in use (n) } & \\ \text { 0-1 drug } & 8(5.6) \\ \text { 2-4 drugs } & 53(37.1) \\ 5-10 \text { drugs } & 76(53.1) \\ >10 \text { drugs } & 6(4.2) \\ \text { Medication regimen complexity index (MRCl) } & \\ \text { Low } & 70(48.9) \\ \text { Medium } & 62(43.3) \\ \text { High } & 11(7.80) \\ & \end{array}$

\section{Comorbidities}

Mental and behavioral disorders (ICD)

$\begin{array}{lc}\text { Insomnia (F51) } & 85(59.4) \\ \text { Anxiety (F06.4) } & 81(56.6) \\ \text { Depression (F32) } & 56(39.2) \\ \text { Depression without treatment (F32) } & 9(6.3) \\ \text { Schizophrenia (F2054) } & 2(1.4) \\ \text { Panic syndrome (F41) } & 1(0.7) \\ \text { Attention deficit hyperactivity disorder (F90) } & 1(0.7)\end{array}$

\begin{tabular}{lc} 
Variable & $\mathbf{n}(\%)$ \\
Diseases of the circulatory system (ICD) & $77(53.8)$ \\
Arterial hypertension (I10) & $17(11.9)$ \\
Stroke (I64) & $8(5.6)$ \\
Infarction (I21.9) & $4(2.8)$ \\
Angina pectoris (I20) & $4(2.8)$ \\
Arrhythmia (I49.9) & \\
Endocrine and metabolic diseases (ICD) & $41(28.7)$ \\
Dyslipidemia (E78) & $35(24.5)$ \\
Diabetes mellitus (E11) & $2316.1)$ \\
Metabolic syndrome & $20(14.0)$ \\
Hypothyroidism (E039) & $17(11.9)$ \\
Obesity (E66) & $10(7.0)$ \\
Deficiency of cholecalciferol (E55) & \\
Nervous system diseases (ICD) & $8(5.6)$ \\
Epilepsy (G40) & $2(1.4)$ \\
Parkinson's disease (G20) & $3(2.1)$ \\
Diseases of the musculoskeletal and connective system (ICD) \\
Osteoporosis (M81.9) & $6(4.2)$ \\
Gout (M10) & $5(3.5)$ \\
Osteoarthritis (M19.9) & $4(2.8)$ \\
Arthritis (M13.9) & $4(2.8)$ \\
Blood diseases and hematopoietic organs (ICD) & \\
Anemia (D50) & $10(7.0)$ \\
Respiratory system diseases (ICD) & \\
Asthma (J45) & $3(2.1)$ \\
Chronic obstructive pulmonary disease (J44.9) & $1(0.7)$ \\
Diseases of the genitourinary system (ICD) & \\
Benign prostatic hyperplasia (N40) & $9(6.4)$ \\
Infectious and parasitic diseases (ICD) & \\
Viral hepatitis C (B18.2) & $1(0.7)$ \\
Neoplasms (ICD) & \\
Prostate cancer (C61) & \\
Breast cancer (C50) & \\
Others & \\
Mean number of morbidities/elderly person & \\
& \\
\hline
\end{tabular}

$I C D=$ International Classification of Diseases; $S D=$ standard deviation.

Table 2. Description of drug therapy for Alzheimer's disease (AD) and defined daily dose, stratified according to disease stage, among elderly people with a diagnosis of Alzheimer's disease $(n=143)$, Araraquara, 2017

\begin{tabular}{|c|c|c|c|c|c|}
\hline Drug therapeutic protocol (ATC) & $\mathrm{n}$ & Cumulative frequency [\%] & $\mathrm{DDD}(\mathrm{mg})$ & Dose used/ day (mg) & n (\%) \\
\hline \multicolumn{6}{|c|}{ Mild stage of Alzheimer's disease $(n=121)$} \\
\hline \multirow[b]{2}{*}{ Galantamine (N06DA04) } & 66 & 46.1 & 16 & 8 & $8(5.6)$ \\
\hline & & & & 16 & $13(9.0)$ \\
\hline \multirow{2}{*}{ Donepezil (N06DA02) } & 48 & 79.7 & 7.5 & 5 & $7(4.9)$ \\
\hline & & & & 10 & $41(28.7)$ \\
\hline \multicolumn{6}{|c|}{ Moderate stage of Alzheimer's disease $(n=16)$} \\
\hline Galantamine + memantine & 10 & 95.8 & - & $24+20$ & $10(7.0)$ \\
\hline Donepezil + memantine & 5 & 99.3 & - & $10+20$ & $5(3.5)$ \\
\hline Rivastigmine + memantine & 1 & 100 & - & $4.5+20$ & $1(0.7)$ \\
\hline \multicolumn{6}{|c|}{ Severe stage of Alzheimer's disease $(n=6)$} \\
\hline
\end{tabular}

ATC $=$ Anatomical Therapeutic Chemical; DDD = defined daily dose; $\mathrm{n}=$ number of elderly. 
Ninety-one of the elderly subjects (63.6\%) used at least one drug that was considered to be a PIM. The mean number of PIMs in use was around two per elderly individual. The incidence of PII was higher among the polymedicated elderly individuals (mean of 2.3 PIIs per elderly person [SD: 1.44]) than among the non-polymedicated individuals (mean of 1.5 PIIs per elderly person [SD: 1.22]).

The most frequently used PIM classes were antipsychotics (44.6\%), such as risperidone and quetiapine; and benzodiazepines (BZD) (27.3\%), such as clonazepam and flunitrazepam. The most frequent PIIs were of drug-illness type. The largest proportion of PIIs came from use of BZD and Z drugs among elderly people with dementia and depression (41.2\%). Additionally, use of antipsychotics without a diagnosis of psychosis (34.5\%) stood out (Table 3). ${ }^{26-31}$

It was observed that $27.3 \%$ [39/143] of the elderly people used benzodiazepine medications for insomnia or anxiety, or as a coadjutant for treating depression, and 3.5\% [5/143] used zolpidem for sleep disorders. Therefore, around one in four elderly people used $\mathrm{BZD}$ after receiving the diagnosis of probable $\mathrm{AD}$.

There were relatives and caregivers who stated that the elderly individuals never used BZD (55), while 16 did not know the history of use. Seventy-one elderly people (49.6\%) stated that they had made use of BZD at some time during their lives. Twenty elderly patients had used it before receiving the diagnosis of $\mathrm{AD}$ and 19 started to use it after receiving this diagnosis: thus, 39 elderly people were using BZD. The BZDs that these individuals had used most during their lives were clonazepam, bromazepam, diazepam and flunitrazepam (long half-life). The length of use of BZDs ranged from one day to 50 years.

Therefore, it was possible to delineate a timeline for the use of benzodiazepines at some point in life, in relation to the diagnosis of probable Alzheimer's disease, among these elderly people. It was observed that the numbers of elderly patients taking BZD before (36) and after (35) receiving the diagnosis of AD were similar (Figure 2).

Only $9.1 \%$ and $1.4 \%$ of the elderly patients declared that they were alcohol users and smokers, respectively. However, 24 elderly people were former alcohol users and 49 former smokers.

After multivariate logistic regression, the severity of $\mathrm{AD}$ was found not to be a risk factor for the presence of the following drug risk variables: PIM use (P-value: 0.6838 ), occurrence of PII (P-value: 0.6838$)$, use of polypharmacy (P-value: 0.0781 ) and occurrence of high-complexity MRCI (P-value: 0.8419 ).

However, from another perspective, simple logistic regression to assess whether the other variables identified in this study were risk factors for AD severity (such as sociodemographic characteristics or comorbidities, among others) showed that polypharmacy was the only possible risk factor for severity (P-value: 0.0206).

In addition, although comorbidities were not associated with $\mathrm{AD}$ severity, it was found that dyslipidemia (P-value: 0.0110), diabetes (P-value: 0.0352), hypertension (P-value: 0.041) and metabolic syndrome (P-value: 0.0376$)$ were associated as risk factors for the presence of at least one of the drug risk variables.

Furthermore, from analysis on all comorbidities according to their ICD-10 classifications, the classes of mental and behavioral disorders (P-value: 0.0109) and circulatory system diseases (P-value: 0.0010$)$ were also found to be associated with the presence of drug risk variables.

\section{DISCUSSION}

Most of the elderly people with $\mathrm{AD}$, in the present study, showed drug risks due to polypharmacy and because they had comorbidities of anxiety, high cholesterol, hypertension, diabetes and metabolic syndrome.

It was observed that the drug therapy for these elderly individuals with $\mathrm{AD}$ was of low or medium complexity. We did not find any studies in the literature that identified or discussed the MRCI among elderly people with AD. However, a recent study showed that cognitive impairment was associated with lower MRCI scores than those of other chronic diseases. ${ }^{32}$

The complexity of drug therapy varies according to the morbidity that elderly patients present. ${ }^{32}$ There are correlations not only with the number of drugs in use, but also with other factors such as dosage form and dosage schedule. ${ }^{24}$

On the other hand, although the drug therapy was assessed as presenting low to medium complexity, most of the elderly patients were using five or more drugs. Moreover, simple logistic regression showed that polypharmacy was the only drug risk factor associated with AD severity. Although we are not aware of any studies that have identified an association between polypharmacy and $\mathrm{AD}$ severity, there have been some recent studies showing that polypharmacy is a risk factor for dementia. ${ }^{33,34}$

Other studies have also correlated polypharmacy with prescription of PIMs ${ }^{1}$ and occurrence of PIIs. ${ }^{3}$ Presence of these factors is associated with increased mortality among elderly people. ${ }^{35,36}$

In the present study, the most commonly used PIM drug classes with PIMs and PIIs were antipsychotics and BZDs. Both of these classes are commonly prescribed for management of behavioral and psychological symptoms of dementia (BPSD). ${ }^{37,38}$

Even though antipsychotics are frequently prescribed for treating BPSD, this is an off-label use of this drug class, according to the Food and Drug Administration, since these are standard drugs for treating schizophrenia. ${ }^{39}$ Opinions regarding the risk/benefit relationship of this use are divergent. While some studies have shown that antipsychotics are efficacious for improvement of BPSD, ${ }^{40}$ others have shown that their use is associated with a more pronounced cognitive and functional decline and a lack of improvement of BPSD. ${ }^{41}$

The BZD class has mainly been prescribed for management of insomnia and anxiety. In contrast, because sleep disorders are usually related to brain changes arising from $\mathrm{AD}$ itself, it is not 
Table 3. Frequency of use of potentially inappropriate medications (PIMs) and occurrence of potentially inappropriate interactions (PIIs), according to the assessment instruments and rationale, among elderly people with a probable diagnosis of Alzheimer's disease ( $n=143$ ), Araraquara, 2017

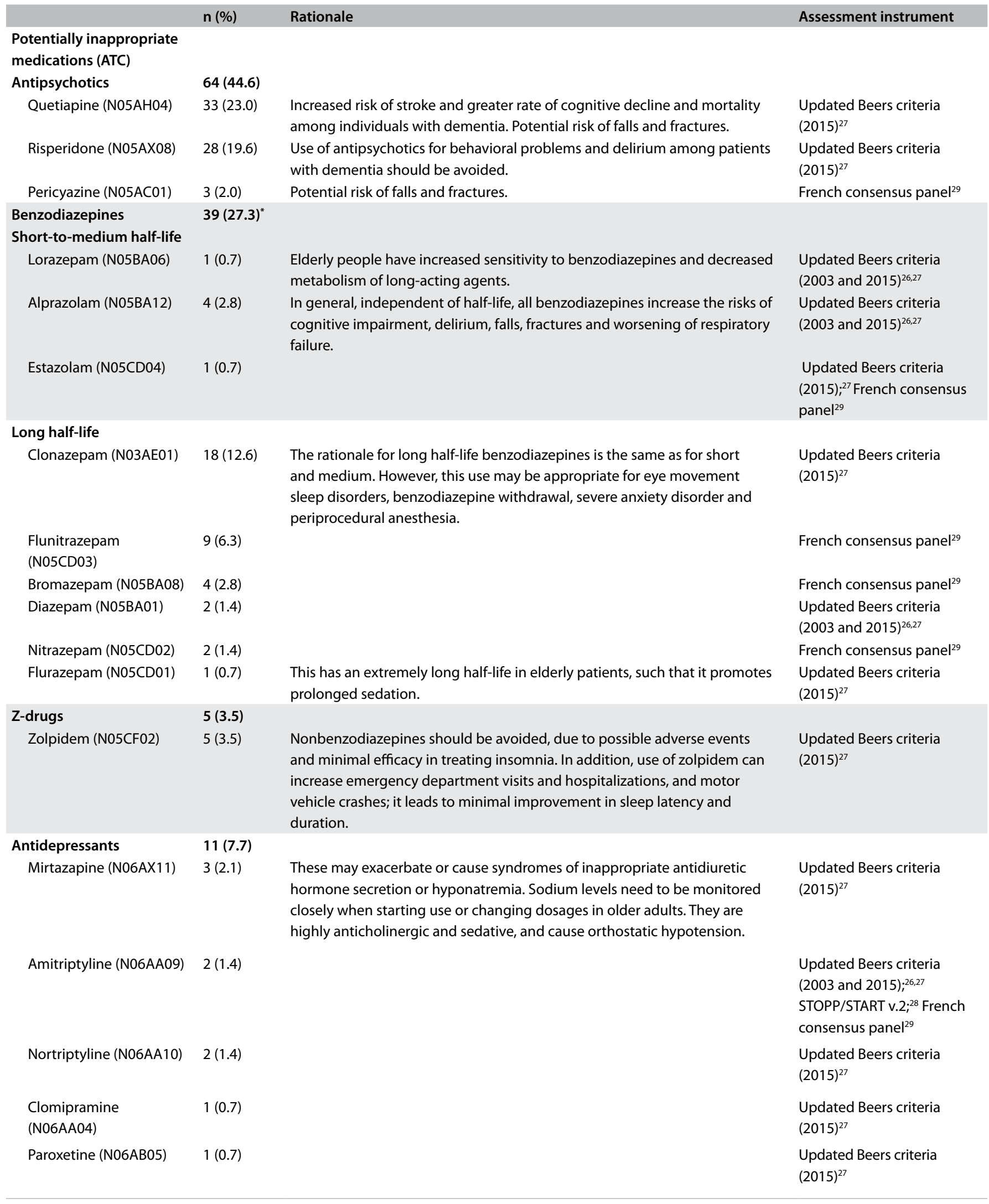


Table 3. Continuation

\begin{tabular}{|c|c|c|}
\hline & n (\%) & Rationale \\
\hline Fluoxetine (N06AB03) & $2(1.4)$ & $\begin{array}{l}\text { This drug carries a risk of producing excessive stimulation of the central } \\
\text { nervous system, sleep disturbances and increased agitation. In addition, } \\
\text { there are risks of ataxia, worsening of psychomotor function and syncope. It } \\
\text { may exacerbate or cause syndromes of inappropriate secretion of antidiuretic } \\
\text { hormone or hyponatremia. }\end{array}$ \\
\hline $\begin{array}{l}\text { Oxcarbazepine } \\
\text { (N03AF02) }\end{array}$ & $1(0.7)$ & $\begin{array}{l}\text { May exacerbate or cause syndromes of inappropriate antidiuretic hormone } \\
\text { secretion or hyponatremia; sodium levels need to be monitored closely when } \\
\text { starting use or changing dosages in older adults. }\end{array}$ \\
\hline Pantoprazole (A02BC02) & $3(2.1)$ & $\begin{array}{l}\text { Avoid scheduled use for }>8 \text { weeks unless for high-risk patients (e.g. oral } \\
\text { corticosteroids or chronic NSAID use) or for erosive esophagitis, Barrett's } \\
\text { esophagitis, pathological hypersecretory condition or demonstrated need for } \\
\text { maintenance treatment (e.g. due to failure of drug discontinuation trial or H2 } \\
\text { blockers). }\end{array}$ \\
\hline Diuretics & $6(4.2)$ & \\
\hline $\begin{array}{l}\text { Spironolactone } \\
\text { (C03DA01) }\end{array}$ & $6(4.2)$ & $\begin{array}{l}\text { In elderly patients with a creatinine clearance of less than } 30 \mathrm{ml} / \mathrm{min} \text {, serum } \\
\text { potassium levels may be increased. }\end{array}$ \\
\hline
\end{tabular}

\section{Antihyperglycemic $\quad 2(1.4)$ \\ Glibenclamide (A10BB01) 2 (1.4) \\ Anti-Parkinsonian \\ $1(0.7)$ \\ Biperiden (N04AA02) \\ $1(0.7)$ \\ All sulfonylureas in general should be avoided among the elderly, because they can cause prolonged hypoglycemia and inappropriate secretion of antidiuretic hormone. \\ Inappropriate for elderly people with dementia and delirium because it may worsen the cognitive and delirium.}

\begin{tabular}{|c|}
\hline Antimicrobial \\
\hline Nitrofurantoin (J01XE01) \\
\hline Antiarrhythmics \\
\hline Amiodarone (C01BD01) \\
\hline
\end{tabular}

Total number of PIMs

Total number of elderly individuals

Average number of PIMs/ elderly individual [SD]

Potentially inappropriate interaction (PII) Morbidity - drug

Use of antipsychotics for non-psychotic diagnosis and in dementia neuropathy or allergic reactions, especially with long-term use. Bacteria resistance in cases of protracted use can be observed. de pointes. Amiodarone is effective for maintaining sinus rhythm but has greater toxicity than other antiarrhythmics used in atrial fibrillation.
The risk/benefit relationship cannot be justified. Use should be avoided, due to adverse events at the central nervous system level.

Assessment instrument

Updated Beers criteria

$(2003)^{26}$

Updated Beers criteria

$(2015)^{27}$

Updated Beers criteria $(2015)^{27}$

Updated Beers criteria $(2015)^{27}$

Updated Beers criteria $(2015)^{27}$

Updated Beers criteria $(2015)^{27}$

Updated Beers criteria (2003 and 2015); ;6,27 French consensus panel ${ }^{29}$ Straand criteria (1999) ${ }^{31}$ Updated Beers criteria (2003 and 2015) $)^{26,27}$

Updated Beers criteria (2015); ${ }^{27}$ STOPP/START v. ${ }^{28}$

Updated Beers criteria (2015), ${ }^{27}$ STOPP/START v. $2 ;{ }^{28}$ French consensus pane ${ }^{29}$

Updated Beers criteria (2003 and 2015); ${ }^{26,27}$ French consensus panel ${ }^{29}$

Updated Beers criteria (2003 and 2015) $)^{26,27}$

Updated Beers criteria $(2015)^{27}$ 
Table 3. Continuation

\begin{tabular}{|c|c|c|c|}
\hline & n (\%) & Rationale & Assessment instrument \\
\hline $\begin{array}{l}\text { Dementia versus use of } \\
\text { benzodiazepines and } \\
\text { benzodiazepine receptor } \\
\text { agonists }\end{array}$ & 41 & $\begin{array}{l}\text { Aggravation of cognitive impairment. Possible adverse drug events at central } \\
\text { level. }\end{array}$ & $\begin{array}{l}\text { Updated Beers criteria } \\
(2015)_{; 7}^{27} \\
\text { French consensus panel }^{29}\end{array}$ \\
\hline $\begin{array}{l}\text { Depression versus } \\
\text { long-term use of } \\
\text { benzodiazepines }\end{array}$ & 32 & May produce or exacerbated depression. & $\begin{array}{l}\text { Updated Beers criteria } \\
(2003)^{26}\end{array}$ \\
\hline $\begin{array}{l}\text { Depression versus active } \\
\text { metabolites of tricyclic } \\
\text { antidepressants }\end{array}$ & 7 & May cause anticholinergic side effects. & $\begin{array}{l}\text { Canada national consensus } \\
\text { panel }^{30}\end{array}$ \\
\hline $\begin{array}{l}\text { Absence of clinical history } \\
\text { of coronary and cerebral } \\
\text { symptoms and vascular } \\
\text { peripheral occlusion; } \\
\text { diabetes mellitus; arterial } \\
\text { hypertension versus use of } \\
\text { acetylsalicylic acid }\end{array}$ & 4 & & STOPP/START v. $2^{28}$ \\
\hline $\begin{array}{l}\text { Dementia versus use of } \\
\text { neuroleptics }\end{array}$ & 3 & Risk of worsening cognitive impairment. & French consensus panel${ }^{29}$ \\
\hline $\begin{array}{l}\text { Cognitive impairment } \\
\text { versus use of barbiturates }\end{array}$ & 2 & Concern about effects on the central nervous system. & $\begin{array}{l}\text { Updated Beers criteria } \\
(2003)^{26}\end{array}$ \\
\hline $\begin{array}{l}\text { Parkinson's disease versus } \\
\text { use of all antipsychotics } \\
\text { except quetiapine }\end{array}$ & 2 & Concern due to their antidopaminergic and cholinergic effects. & $\begin{array}{l}\text { Updated Beers criteria } \\
(2003)^{26,27}\end{array}$ \\
\hline $\begin{array}{l}\text { Diabetes mellitus versus } \\
\text { use of corticosteroids }\end{array}$ & 1 & May worsen diabetes mellitus; serum glucose levels need to be monitored. & $\begin{array}{l}\text { Canada national consensus } \\
\text { panel }^{30}\end{array}$ \\
\hline $\begin{array}{l}\text { Average number of PIIs/ } \\
\text { elderly individual [SD] }\end{array}$ & $2[1.42]$ & & \\
\hline
\end{tabular}

$\mathrm{n}=$ number of elderly; SD = standard deviation; $\mathrm{ATC}=$ Anatomical Therapeutic Chemical.

*An elderly person can make use of more than one BZD simultaneously; **CNS (central nervous system)-active drugs: antipsychotics, benzodiazepines, nonbenzodiazepines, tricyclic antidepressants, selective serotonin reuptake inhibitors and opioids.

clear whether the drugs actually used are effective, since the use of these drugs in the context of comorbid neurological disease is also considered to be off-label. ${ }^{42,43}$

With regard to chronic use of BZD as a risk factor for $\mathrm{AD}$, a recent meta-analysis showed that its use was a risk factor. ${ }^{44}$ From another perspective, a systematic review identified studies in which negative effects from BZD on the cognition of elderly people who already had the diagnosis of $\mathrm{AD}$ were reported. ${ }^{45}$

However, we did not find any association between use of $\mathrm{BZD}$ and cognitive impairment or progression of $\mathrm{AD}$. This may be explained by the chronic use of BZD before and after the diagnosis of $\mathrm{AD}$ was made, the absence of the clinical parameters of MMSE and CDR and the small sample size.

In addition, it was observed that MetS and its risk factors (cholesterol, hypertension and diabetes) and anxiety (a comorbidity that is considered to be a prodromal symptom of $\mathrm{AD}$ ) were associated with drug risk.

MetS was previously shown to be a risk factor for AD. ${ }^{46,47}$ Its presence allowed the trajectory of the prodromal stage of $\mathrm{AD}$ to become significantly extended to the symptomatic stage. ${ }^{46}$ BPSD have been found to be present both before the diagnosis and during the course of the disease. ${ }^{37}$ 
Anxiety was an aggravating factor for drug safety among the elderly individuals with $\mathrm{AD}$ in the present study and was usually treated with BZD. MetS risk factors were treated with immediate-release nifedipine, propranolol and glibenclamide, and all of these were considered to be PIMs. Nevertheless, these PIMs have been standardized as essential by the WHO and by RENAME-Brazil. However, their respective safer therapeutic equivalents for the elderly, i.e. captopril, losartan and metformin, have also been standardized.

Another important finding from the present study was the absence of determinations of clinical MMSE and CDR parameters among the patients. These findings show that no monitoring of the effectiveness of this drug therapy was being done and, consequently, that there was non-compliance with the guidelines recommended in the PCDTDA/MS. ${ }^{48}$ Therefore, the "minor" complexity of the drug therapy for these elderly individuals with AD did not mean that there were no safety issues or drug-related problems (DRPs) to be identified, prevented, monitored and resolved.

In this context, medication therapy management based on the underlying disease, taking into account the comorbidities and therapeutic experience of the patient and family/caregiver, may be form of pharmaceutical care that would be of interest for promoting drug safety, compliance with drug therapy ${ }^{49}$ and resolution of DRPs. ${ }^{50,51}$

Thus, important data about the drug safety of patients with Alzheimer's disease were identified through the present study. Our findings suggest that patients with AD should be regarded in an overall manner: not only managing the number of drugs in

Diagnosis of Alzheimer's disease

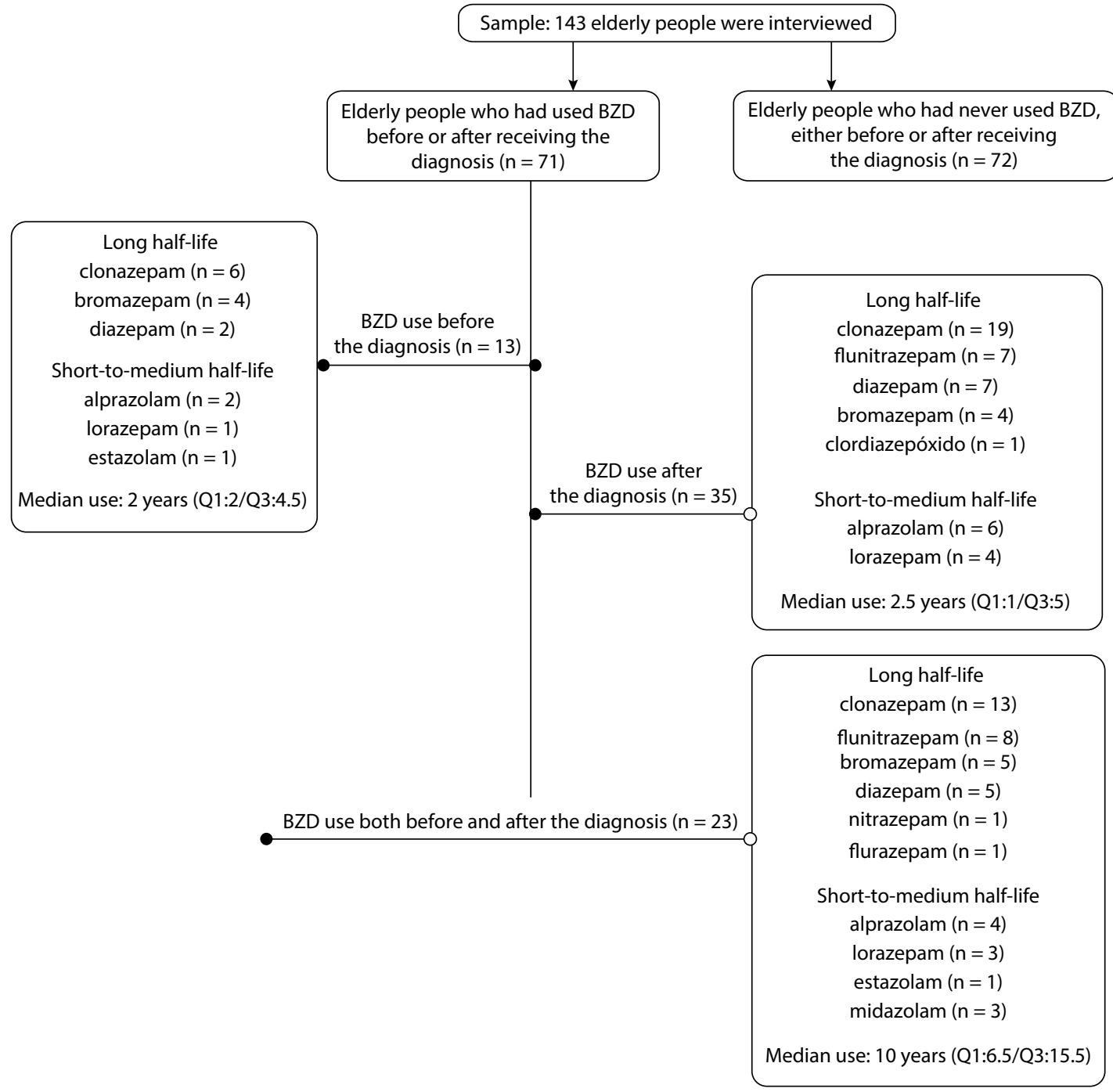

Figure 2. Description of the use of benzodiazepines (BZD) during the patients' lives, in relation to their diagnoses of Alzheimer's disease $(\mathrm{n}=143)$, Araraquara, 2017. 
use or the complexity of drug therapy, but also taking into account the patient's needs and comorbidities, along with the experience and expectations of the caregiver/familiar regarding the treatment, and the outcomes when drug risk variables are present.

\section{Limitations of this study}

The main limitation of this study was that the severity of $\mathrm{AD}$ was assessed through insertion of memantine, because of absence of the clinical parameters of MMSE and CDR. These clinical parameters are considered to be the gold standard and should be ascertained every six months, as recommended by PCDTDA/MS.

Another limitation was the losses of the present study. However, inclusion in this study of incomplete data obtained through interviews with family members/caregivers who were unaware of the clinical history of the elderly patients would have constituted a form of bias. Nonetheless, this inclusion would have diminished the limitations.

Moreover, the cross-sectional design of this study did not allow us to identify causal associations.

\section{CONCLUSION}

Even though the drug therapy of our elderly patients with $\mathrm{AD}$ was of low complexity, the majority of these drugs presented safety risks in relation to the comorbidities of anxiety, cholesterol, hypertension, diabetes and metabolic syndrome. Although we did not identify any evidence in the literature that would correlate polypharmacy with $\mathrm{AD}$ severity, our data suggest that this is a possible drug safety risk. Off-label use of PIMs, such as risperidone, quetiapine and benzodiazepines like clonazepam and flunitrazepam, also present a drug safety risk for elderly people with $\mathrm{AD}$.

\section{REFERENCES}

1. Shade MY, Berger AM, Chaperon C, et al. Factors Associated With Potentially Inappropriate Medication Use in Rural, Community-Dwelling Older Adults. J Gerontol Nurs. 2017;43(9):21-30. PMID: 28399319; doi: 10.3928/00989134-20170406-01.

2. Alves-Conceição V, Rocha KSS, Silva FVN, et al. Medication Regimen Complexity Measured by MRCl: A Systematic Review to Identify Health Outcomes. Ann Pharmacother. 2018;52(11):1117-34. PMID: 29756471; doi: 10.1177/1060028018773691.

3. Varallo FR, Costa MA, Mastroianni P de C. Potenciais interações medicamentosas responsáveis por internações hospitalares. Rev Ciencias Farm Basica e Apl. 2013;34(1):79-85. Available from: http:// hdl.handle.net/11449/107431. Accessed in 2019 (Oct 24).

4. Fried TR, O'Leary J, Towle V, et al. Health outcomes associated with polypharmacy in community-dwelling older adults: a systematic review. J Am Geriatr Soc. 2014;62(12):2261-72. PMID: 25516023; doi: 10.1111/ jgs.13153.
5. Chen YC, Fan JS, Chen MH, et al. Risk factors associated with adverse drug events among older adults in emergency department. Eur J Intern Med. 2014;25(1):49-55. PMID: 24200546; doi: 10.1016/j.ejim.2013.10.006.

6. Salvi F, Marchetti A, D'Angelo F, et al. Adverse drug events as a cause of hospitalization in older adults. Drug Saf. 2012;35(Suppl 1):29-45. PMID: 23446784; doi: 10.1007/BF03319101.

7. Varallo FR, Capucho HC, Silva Planeta CD, Carvalho Mastroianni PD. Possible adverse drug events leading to hospital admission in a Brazilian teaching hospital. Clinics (Sao Paulo). 2014;69(3):163-7. PMID: 24626940; doi: 10.6061/clinics/2014(03)03.

8. O'Mahony D, Gallagher PF. Inappropriate prescribing in the older population: need for new criteria. Age Ageing. 2008;37(2):138-41. PMID: 18349010; doi: 10.1093/ageing/afm189.

9. Dormann H, Sonst A, Müller F, et al. Adverse drug events in older patients admitted as an emergency: the role of potentially inappropriate medication in elderly people (PRISCUS). Dtsch Arztebl Int. 2013;110(13):213-9. PMID: 23596501; doi: 10.3238/arztebl.2013.0213.

10. Albert SM, Colombi A, Hanlon J. Potentially inappropriate medications and risk of hospitalization in retirees: analysis of a US retiree health claims database. Drugs Aging. 2010;27(5):407-15. PMID: 20450238; doi: 10.2165/11315990-000000000-00000.

11. Varallo FR, Oliveira FM, Mastroianni PC. Safety assessment of essential medicines for elderly people: a bibliographic survey. Brazilian J Pharm Sci. 2014;50(2):269-84. doi: 10.1590/S1984-82502014000200006.

12. World Health Organization (WHO). Dementia [Internet]. WHO; 2019. Available from: http://www.who.int/mediacentre/factsheets/fs362/ en/. Accessed in 2019 (Oct 24).

13. Burns A, lliffe S. Alzheimer's disease. BMJ. 2009;338:b158. PMID: 19196745; doi: 10.1136/bmj.b158.

14. Bosboom PR, Alfonso H, Almeida OP, Beer C. Use of Potentially Harmful Medications and Health-Related Quality of Life among People with Dementia Living in Residential Aged Care Facilities. Dement Geriatr Cogn Dis Extra. 2012;2(1):361-71. PMID: 23277778; doi: 10.1159/000342172.

15. Lau DT, Mercaldo ND, Shega JW, Rademaker A, Weintraub S. Functional decline associated with polypharmacy and potentially inappropriate medications in community-dwelling older adults with dementia. Am J Alzheimers Dis Other Demen. 2011;26(8):606-15. PMID: 22207646; doi: $10.1177 / 1533317511432734$

16. Montastruc F, Gardette V, Cantet C, et al. Potentially inappropriate medication use among patients with Alzheimer disease in the REAL. FR cohort: be aware of atropinic and benzodiazepine drugs! Eur J Clin Pharmacol. 2013;69(8):1589-97. PMID: 23588564; doi: 10.1007/s00228013-1506-8.

17. Renom-Guiteras A, Thürmann PA, Miralles R, et al. Potentially inappropriate medication among people with dementia in eight European countries. Age Ageing. 2018;47(1):68-74. PMID: 28985257; doi: 10.1093/ageing/afx147.

18. von Elm E, Altman DG, Egger $M$, et al. The Strengthening the Reporting of Observational Studies in Epidemiology (STROBE) statement: guidelines 
for reporting observational studies. J Clin Epidemiol. 2008;61 (4):344-9. PMID: 18313558; doi: 10.1016/j.jclinepi.2007.11.008.

19. Costa AF, Chaves MLF, Picon PD, et al. Protocolo Clínico e Diretrizes Terapêuticas - Doença de Alzheimer. Portaria Conjunta № 13, de 28 de novembro de 2017 [Internet]. 2017;147-67.

20. Frota NAF, Nitrini R, Damasceno BP, et al. Criteria for the diagnosis of Alzheimer's disease: Recommendations of the Scientific Department of Cognitive Neurology and Aging of the Brazilian Academy of Neurology. Dement Neuropsychol. 2011;5(3):146-52. PMID: 29213739; doi: 10.1590/ S1980-57642011DN05030002.

21. Folstein MF, Folstein SE, McHugh PR. "Mini-mental state". A practical method for grading the cognitive state of patients for the clinician. J Psychiatr Res. 1975;12(3):189-98. PMID: 1202204; doi: 10.1016/00223956(75)90026-6.

22. Hughes CP, Berg L, Danziger WL, Coben LA, Martin RL. A new clinical scale for the staging of dementia. Br J Psychiatry 1982;140:566-72. PMID: 7104545; doi: 10.1192/bjp.140.6.566.

23. National Cholesterol Education Program (NCEP) Expert Panel on Detection, Evaluation, and Treatment of High Blood Cholesterol in Adults (Adult Treatment Panel III). Third Report of the National Cholesterol Education Program (NCEP) Expert Panel on Detection, Evaluation, and Treatment of High Blood Cholesterol in Adults (Adult Treatment Panel III) final report. Circulation. 2002;106(25):3143-421. PMID: 12485966.

24. Melchiors AC, Correr CJ, Fernández-Llimos F. Translation and validation into Portuguese language of the medication regimen complexity index. Arq Bras Cardiol. 2007;89(4):210-8. PMID: 17992376; doi: 10.1590/ s0066-782×2007001600001.

25. Paquin AM, Zimmerman KM, Kostas TR, et al. Complexity perplexity: a systematic review to describe the measurement of medication regimen complexity. Expert Opin Drug Saf. 2013;12(6):829-40. PMID: 23984969; doi: 10.1517/14740338.2013.823944.

26. Fick DM, Cooper JW, Wade WE, et al. Updating the Beers criteria for potentially inappropriate medication use in older adults: results of a US consensus panel of experts. Arch Intern Med. 2003;163(22):2716-24. PMID: 14662625; doi: 10.1001/archinte.163.22.2716.

27. American Geriatrics Society 2015 Beers Criteria Update Expert Panel. American Geriatrics Society 2015 Updated Beers Criteria for Potentially Inappropriate Medication Use in Older Adults. J Am Geriatr Soc. 2015;63(11):2227-46. PMID: 26446832; doi: 10.1111/jgs.13702.

28. O'Mahony D, O'Sullivan D, Byrne $S$, et al. STOPP/START criteria for potentially inappropriate prescribing in older people: version 2. Age Ageing. 2015;44(2):213-8. PMID: 25324330; doi: 10.1093/ageing/ afu145.

29. Laroche ML, Charmes JP, Merle L. Potentially inappropriate medications in the elderly: a French consensus panel list. Eur J Clin Pharmacol. 2007;63(8):725-31. PMID: 17554532; doi: 10.1007/s00228-007-0324-2.

30. McLeod PJ, Huang AR, Tamblyn RM, Gayton DC. Defining inappropriate practices in prescribing for elderly people: a national consensus panel. CMAJ. 1997;156(3):385-91. PMID: 9033421.
31. Straand, J, Rokstad KS. Elderly patients in general practice: diagnoses, drugs and inappropriate prescriptions. A report from the Møre \& Romsdal Prescription Study. Fam Pract. 1999;16(4):380-8. PMID: 10493709; doi: 10.1093/fampra/16.4.380.

32. Bellostas-Muñoz L, Díez-Manglano J. Complexity of the medication regimen for polypathological patients. Rev Clin Esp. 2018;218(7):34250. PMID: 29784546; doi: 10.1016/j.rce.2018.04.009.

33. Leelakanok N, D'Cunha RR. Association between polypharmacy and dementia - A systematic review and metaanalysis. Aging Ment Health. 2019;23(8):932-41. PMID: 29746153; doi: 10.1080/13607863.2018.1468411.

34. Park HY, Park JW, Song HJ, Sohn HS, Kwon JW. The Association between Polypharmacy and Dementia: A Nested Case-Control Study Based on a 12-Year Longitudinal Cohort Database in South Korea. PLoS One. 2017;12(1):e0169463. PMID: 28056068; doi: 10.1371/journal. pone.0169463.

35. Muhlack DC, Hoppe LK, Weberpals J, Brenner H, Schöttker B. The Association of Potentially Inappropriate Medication at Older Age With Cardiovascular Events and Overall Mortality: A Systematic Review and Meta-Analysis of Cohort Studies. J Am Med Dir Assoc. 2017;18(3):21120. PMID: 28131719; doi: 10.1016/j.jamda.2016.11.025.

36. Cross AJ, George J, Woodward MC, et al. Potentially Inappropriate Medication, Anticholinergic Burden, and Mortality in People Attending Memory Clinics. J Alzheimers Dis. 2017;60(2):349-58. PMID: 28869467; doi: 10.3233/JAD-170265.

37. Amieva H, Le Goff M, Millet X, et al. Prodromal Alzheimer's disease: successive emergence of the clinical symptoms. Ann Neurol. 2008;64(5):492-8. PMID: 19067364; doi: 10.1002/ana.21509.

38. Martinez C, Jones RW, Rietbrock S. Trends in the prevalence of antipsychotic drug use among patients with Alzheimer's disease and other dementias including those treated with antidementia drugs in the community in the UK: a cohort study. BMJ Open. 2013;3(1). pii: e002080. PMID: 23299113; doi: 10.1136/bmjopen-2012-002080.

39. Mastroianni P de C, Polli LM, Trombotto V, Varallo FR. Risperidona ou Quetiapina em pacientes com diagnóstico provável de Doença de Alzheimer? Journal of Applied Pharmaceutical Sciences - JAPHAC; 2017;4(3):35-41. Available from: http://docs.wixstatic.com/ugd/e6f2ee _95020ebea79a4aea99365f3e8e605c48.pdf. Accessed in 2020 (Feb 21).

40. Ballard C, Waite J. The effectiveness of atypical antipsychotics for the treatment of aggression and psychosis in Alzheimer's disease. Cochrane Database Syst Rev. 2006;(1):CD003476. PMID: 16437455; doi: 10.1002/14651858.CD003476.pub2.

41. Rosenberg PB, Mielke MM, Han D, et al. The association of psychotropic medication use with the cognitive, functional, and neuropsychiatric trajectory of Alzheimer's disease. Int J Geriatr Psychiatry. 2012;27(12):124857. PMID: 22374884; doi: 10.1002/gps.3769.

42. Mayer G, Jennum P, Riemann D, Dauvilliers Y. Insomnia in central neurologic diseases--occurrence and management. Sleep Med Rev. 2011;15(6):369-78. PMID: 21481621; doi: 10.1016/j.smrv.2011.01.005. 
43. McCleery J, Cohen DA, Sharpley AL. Pharmacotherapies for sleep disturbances in dementia. Cochrane Database Syst Rev. 2016;11:CD009178. PMID: 27851868; doi: 10.1002/14651858.CD009178. pub3.

44. Lucchetta RC, da Mata BPM, Mastroianni PC. Association between Development of Dementia and Use of Benzodiazepines: A Systematic Review and Meta-Analysis. Pharmacotherapy. 2018; 38(10):1010-20. PMID: 30098211; doi: 10.1002/phar.2170.

45. Defrancesco M, Marksteiner J, Fleischhacker WW, Blasko I. Use of Benzodiazepines in Alzheimer's Disease: A Systematic Review of Literature. Int J Neuropsychopharmacol. 2015;18(10):pyv055. PMID: 25991652; doi: 10.1093/ijnp/pyv055.

46. Pugazhenthi S. Metabolic Syndrome and the Cellular Phase of Alzheimer's Disease. Prog Mol Biol Transl Sci. 2017;146:243-58. PMID: 28253987; doi: 10.1016/bs.pmbts.2016.12.016.

47. Razay G, Vreugdenhil A, Wilcock G. The metabolic syndrome and Alzheimer disease. Arch Neurol. 2007;64(1):93-6. PMID: 17210814; doi: 10.1001/archneur.64.1.93.

48. Forgerini M, Mastroianni P de C. Monitoring compliance of Clinical Protocol and Therapeutic Guidelines for Alzheimer's disease. Dement Neuropsychol. 2020;14(1):24-7. doi: 10.1590/1980-57642020dn14010004

49. Mastroianni PC, Forgerini M. Compliance and drug-related problems in probable Alzheimer's disease elderly. Int Psychogeriatr. 2019;1-2. PMID: 30722799; doi: 10.1017/S104161021800234X.

50. Mastroianni PC, Forgerini M. Drug administration adjustments for elderly patients with dysphagia: A case report. Dement Neuropsychol. 2018;12(1):97-100. PMID: 29682241; doi: 10.1590/1980-57642018dn12010015.

51. Forgerini M, Lucchetta RC, Oliveira FM, et al. Impact of pharmacist intervention in patients with Alzheimer's disease. Braz J Pharm Sci. 2020 , in press.

Authors' contributions: Marcela Forgerini conducted the study; collected, tabulated and discussed the data; and drafted and reviewed the manuscript. Maria Teresa Herdeiro and José Carlos Fernandes Galduróz participated in the data discussion and critically reviewed the manuscript. Patrícia de Carvalho Mastroianni delineated the study; discussed the tabulation, data and analysis; and wrote and critically reviewed the manuscript. All authors reviewed and approved the final version of this manuscript

Acknowledgements: Fundação de Amparo à Pesquisa do Estado de São Paulo (FAPESP), Conselho Nacional de Desenvolvimento Tecnológico (CNPq) and Coordenação de Aperfeiçoamento de Pessoal de Nível Superior - Brasil (CAPES)
Sources of funding: This work was supported by the Fundação de Amparo à Pesquisa do Estado de São Paulo (FAPESP) [grant numbers 2013/12681-2; 2018/07501-9]; Conselho Nacional de Desenvolvimento Tecnológico (CNPq) [459461/2014-1; 131206/2017-6] and Coordenação de Aperfeiçoamento de Pessoal de Nível Superior - Brasil (CAPES) - finance code 001

Conflict of interest: There were no conflicts of interest

Date of first submission: October 23, 2019

Last received: January 17, 2020

Accepted: February 19, 2020

\section{Address for correspondence:}

Patrícia de Carvalho Mastroianni

Departamento de Fármacos e Medicamentos, Faculdade de Ciências Farmacêuticas da Universidade Estadual Paulista (UNESP)

Rodovia Jaú, Km 01 s/no

CEP 14800-901

Araraquara (SP) - Brasil

Tel. (+55 16) 3301-6977

E-mail: patriciamastroianni@yahoo.com.br 